\title{
The dynamics of ice melting in the conditions of crybot movement
}

\author{
Ekaterina Zakharova ${ }^{1,{ }^{*}}$, Arkadii Zakharevich ${ }^{1}$, and Nadegda Gutareva ${ }^{1}$ \\ ${ }^{1}$ National Research Tomsk Polytechnic University, 634050 Tomsk, Russia
}

\begin{abstract}
The mathematical modeling results of the simultaneous processes of heat and mass transfer under the conditions of intense phase changes (melting of ice) during the movement of cryobot have been given. The spatial unevenness of the melting rate of ice has been taken into account. It has been established that the rate of passage of the cryobot depends essentially on its temperature. According to the results of the numerical simulation, considerable cooling of the cryobot sheath has been established. The latter is due to the high endothermic effect of melting ice.
\end{abstract}

\section{Introduction}

The study of the modern continental glaciation and all types of glaciers is of great importance for microbiology, geophysics, geology and other natural sciences [1]. At the moment, there are several directions in the study of glaciation. The most important for today is the study of the current state of the glaciers in Antarctica. Due to the fact that the problem of warming is global every year the situation worsens. About $30 \cdot 10^{6} \mathrm{~km}^{3}$ ice is concentrated in Antarctica, and with such a rapid increase in temperature in the near future, a large-scale melting of these glaciers is possible. The latter will affect significantly the ecosystem, both the mainland and the entire world ocean. The level of the world ocean will also change significantly. In this regard, a careful study of the structure and the state of the glaciers is necessary [2].

One of the more effective ways of studying the structure, the material composition and the dynamics of ice deposits is drilling wells and analyzing ice cores. This process can be carried out in three ways: the first variant involves the thermal destruction of ice structures [3]; the second variant involves the use of mechanical action on the layers of ice ("classical" drilling) [2]; the third variant is based on the combined chemical and thermal effects [1]. To obtain an ecologically pure sample of the ice core, it is expedient to use exclusively the thermal method of drilling a well [4].

When studying the large ice arrays and objects located below them, the apparatus must meet the criteria: the minimum possible size and weight, the presence of a powerful energy source. These requirements are fully consistent with the cryobot - a specialized proberobot of deep glacial penetration. The main advantages of a cryobot with respect to other devices are the smaller vulnerability of the device to damage, relatively small energy costs. The movement of the drilling machine is carried out by heating the ice to the formation of

\footnotetext{
Corresponding author: eaz15@,tpu.ru
} 
melt water in front of the bow. Water flows around the cryobat and freezes behind it, while the cryobot itself continues to move under the influence of gravity. In this connection, it is of interest to study the heat transfer in the conditions of melting of the large ice masses by local heat sources.

In the conditions of Antarctica (the significant distance, the heterogeneous structure of ice, the extremely severe climate, the total impassability and scale of the objects of study) carrying out the field experiments will be either very expensive, or in some cases even an impossible process. In these conditions, the most acceptable is the application of the mathematical modeling. However, by the present time, a mathematical apparatus has not been developed practically that provides the possibility of solving the problem of modeling the motion of cryobot in the thickness of the extended ice structures. The known mathematical models, as a rule, are based on a number of substantially simplifying assumptions.

For example, in [2] the results of the computer simulation of the processes of heat and mass transfer during the motion of the cryobot through the water ice massifs are presented. In this case, the mathematical formulation [2] does not imply the presence of an ice-water system (the fusion front) in the vicinity of the apparatus. The absorption of heat as a result of the recrystallization of the ice structures is described in the framework of the enthalpy heat transfer model. In [3,5], the mathematical model of heat transfer processes in ice structures is shown in the melting of the latter. However, the model $[3,5]$ is based on the hypothesis of the uniformity of the distribution of the fusion front over the entire ice sheet. The most complete is the model [6]. However, the latter describes the melting process in the framework of the approach based on the dynamically adaptive difference grids. This approach is very complicated and requires the use of a special mathematical apparatus. In addition, the use of the method of [6] requires the special control functions, the significance of which can only be found from the experiment. Such an insignificant number of the works on modeling of the motion of cryobot is associated with the high complexity of modeling the processes of phase transformations (melting of ice) in the multidimensional formulation of the problem (the so-called multi-front problems of Stefan) [5, 7]. It can be said that the development of a mathematical apparatus that provides the predictive modeling of the processes of heat transfer in the conditions of melting ice during the movement of cryobot in ice formations is an actual and unresolved task to date.

The aim of this work is the mathematical modeling of heat transfer processes that occur together under ice melting conditions during the movement of the cryobot.

\section{Physical statement}

At the initial moment of time, a massive heat source acts on the ice surface on a limited area. As a result, the ice layer starts to heat up. When the ice structure reaches the temperature equal to the phase transition temperature, the process of melting of the ice cover is initiated. The melting front moves deeper into the ice. As a consequence, in the solution area of the problem, a heterogeneous structure is formed, consisting of a solid and a liquid phase of water, with the significantly different thermal properties [7, 8]. In solving the problem, ice has been assumed to be homogeneous. At the initial time, the temperature of the entire volume of ice has been assumed to be the same.

\section{Mathematical statement}

The mathematical formulation of the problem, corresponding to the above physical model, consists of the following system of the equations. The energy equation for the "ice-water" 
system, taking into account the endothermic effect of the melting process (by analogy with $[5,9,12])$ :

$$
c(T) \rho(T) \frac{\partial T}{\partial t}=\frac{\partial}{\partial x} \lambda(T) \frac{\partial T}{\partial x}+\frac{\partial}{\partial y} \lambda(T) \frac{\partial T}{\partial y}-\frac{Q W}{h_{d}} \delta\left(x_{m e l t}, y_{m e l t}\right),
$$

where $c$-heat capacity $\mathrm{kJ} /(\mathrm{kg} \cdot \mathrm{K}) ; \rho$ - density, $\mathrm{kg} / \mathrm{m}^{3} ; \lambda$ - thermal conductivity, $W /$ $(\mathrm{m} \cdot \mathrm{K}) ; h_{d}$ - Smearing front smearing parameter; $W$ - Melting rate $\mathrm{kg} /\left(\mathrm{m}^{2} \mathrm{~s}\right) ; Q-$ Melting heat of ice $\mathrm{J} / \mathrm{kg} ; T-$ temperature, $K ; \delta-$ Dirac delta function. [11] The value of thermophysical properties is determined from the conditions for localization of the fusion front.

The equation energy for cryobot:

$$
c_{c} \rho_{c} \frac{\partial T}{\partial t}=\lambda_{c}\left(\frac{\partial^{2} T}{\partial x^{2}}+\frac{\partial^{2} T}{\partial y^{2}}\right)+Q_{v}
$$

where $c_{c} \rho_{c}, \lambda_{c}-$ heat capacity, density and thermal conductivity of cryobot; $Q_{v}-$ power heat source, $\mathrm{W} / \mathrm{m}^{3}$. [10] The mathematical statement also includes the corresponding boundary conditions (Fig. 1):

$$
\begin{aligned}
& \mathrm{t}=0 ; 0<\mathrm{x}<\mathrm{l} ; 0<\mathrm{y}<\mathrm{H} ; \mathrm{T}(\mathrm{x}, \mathrm{y})=\mathrm{T}_{\mathrm{f}} \\
& \mathrm{t}=0 ; 0<\mathrm{x}<\mathrm{l} ; 0<\mathrm{y}<\mathrm{H} ; \mathrm{T}(\mathrm{x}, \mathrm{y})=\mathrm{T}_{\mathrm{cr}} \\
& \left.\frac{\partial \mathrm{T}}{\partial \mathrm{x}}\right|_{\mathrm{x}=0} ^{0<\mathrm{y}<H}=0 ;\left.\frac{\partial \mathrm{T}}{\partial \mathrm{y}}\right|_{\mathrm{y}=0} ^{0<x<l}=0 ;\left.\lambda(T) \frac{\partial \mathrm{T}}{\partial \mathrm{y}}\right|_{0<\mathrm{x}<\mathrm{x}_{1}} ^{\mathrm{y}=\mathrm{H}}=\alpha\left(T_{e}-T\right) ; \\
& \left.\lambda(T) \frac{\partial \mathrm{T}}{\partial \mathrm{y}}\right|_{\mathrm{x}_{2}<x<l} ^{\mathrm{y}=\mathrm{H}}=\alpha\left(T_{e}-T\right) ;\left.\lambda(T) \frac{\partial \mathrm{T}}{\partial \mathrm{y}}\right|_{\mathrm{y}=\mathrm{H}} ^{\mathrm{x}_{1}<x<\mathrm{x}_{2}}=\left.\lambda_{c} \frac{\partial \mathrm{T}}{\partial \mathrm{y}}\right|_{\mathrm{y}=\mathrm{H}} ^{\mathrm{x}_{1}<x<\mathrm{x}_{2}} ; \\
& \left.\lambda(T) \frac{\partial \mathrm{T}}{\partial \mathrm{x}}\right|_{\mathrm{H}<\mathrm{y}<\mathrm{H}_{1}} ^{\mathrm{x}=\mathrm{x}_{1}}=\alpha\left(T_{e}-T\right) ;\left.\lambda(T) \frac{\partial \mathrm{T}}{\partial \mathrm{x}}\right|_{\mathrm{H}<\mathrm{y}<\mathrm{H}_{1}} ^{\mathrm{x}=\mathrm{x}_{2}}=\alpha\left(T_{e}-T\right) ; \\
& \lambda(T) \frac{\partial T}{\partial x}=\lambda_{c} \frac{\partial T}{\partial x} ; \lambda_{c} \frac{\partial T}{\partial x}=\lambda(T) \frac{\partial T}{\partial x}
\end{aligned}
$$

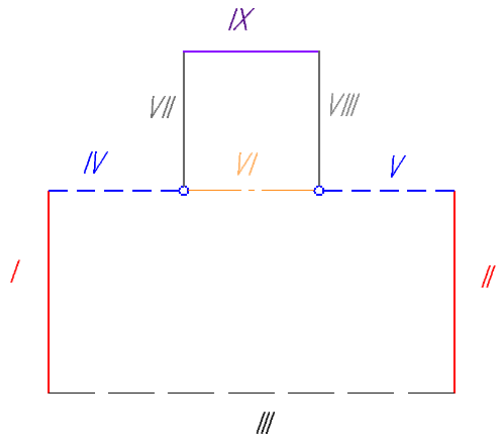

Fig.1 Areas for solving the problem.

\section{The results}

According to the results of the mathematical modeling of cryobot movement, the formation of a vertical shaft with even edges has been established. Figures 2 a. $2 b$ and $3 a, 3 b$ show the temperature fields in the "cryobot-ice" system with varying widths and heights of a cryobot. The initial temperature of the apparatus is $\mathrm{T}=500 \mathrm{~K}$. The analysis of figure 2 shows that with increasing width of the thermal drilling machine, the temperature distribution in the latter becomes uniform. In this case, the values of $\mathrm{T}$ at each point of space are substantially reduced (up to $\mathrm{T}=350 \mathrm{~K}$ ). This is due to the influence of the phase 
transformations (melting of the ice structures) on the characteristics of heat transfer in the cover of the apparatus.

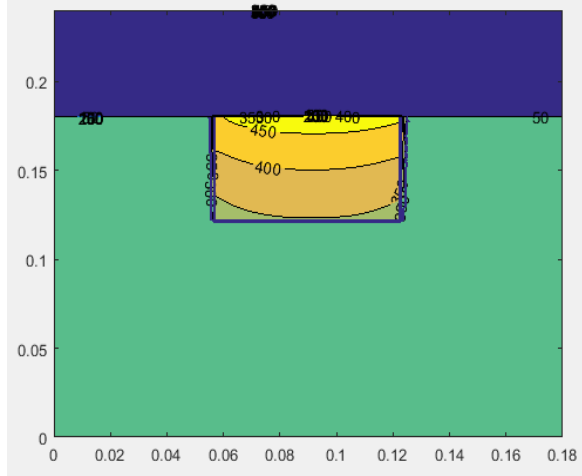

(a)

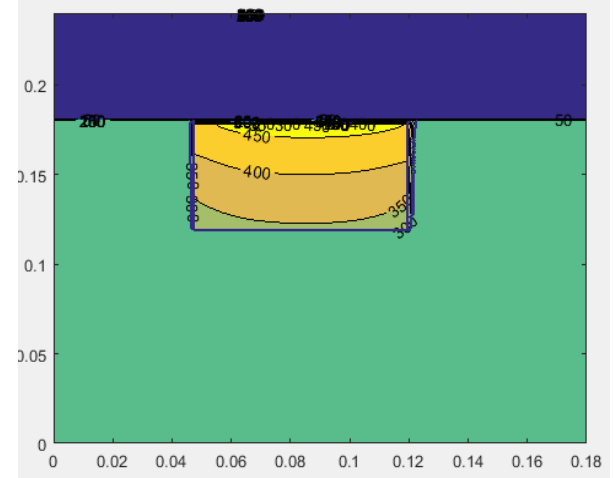

(b)

Fig. 2. (a) The temperature field in the "ice-cryobot" system with a width of the last $0.06 \mathrm{~m}$. (b)The temperature field in the "cryobot-ice" system at a width of $0.084 \mathrm{~m}$.

Figures $3 \mathrm{a}$ and $3 \mathrm{~b}$ show the temperature distributions in the ice-cryobot system under the conditions of its movement through the ice thickness with varying altitude apparatus. The analysis of figures $3 \mathrm{a}$ and $3 \mathrm{~b}$ shows that an increase in the height of the cryobot leads to less cooling of the cover of the apparatus. Accordingly, it can reasonably be assumed that for a stable movement, the cryobot must have the geometric characteristics that ensure a slow cooling of the cover.

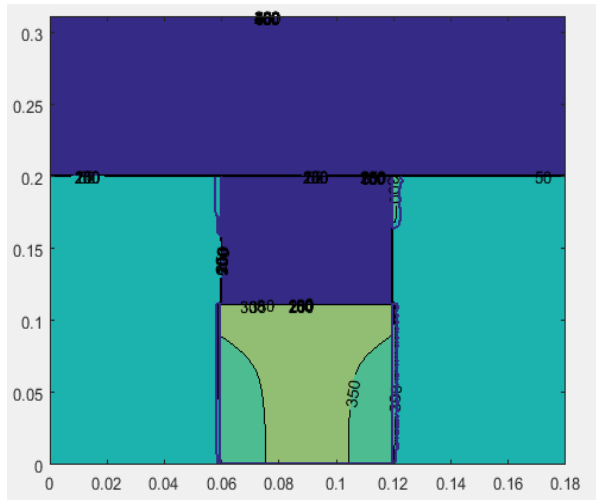

(a)

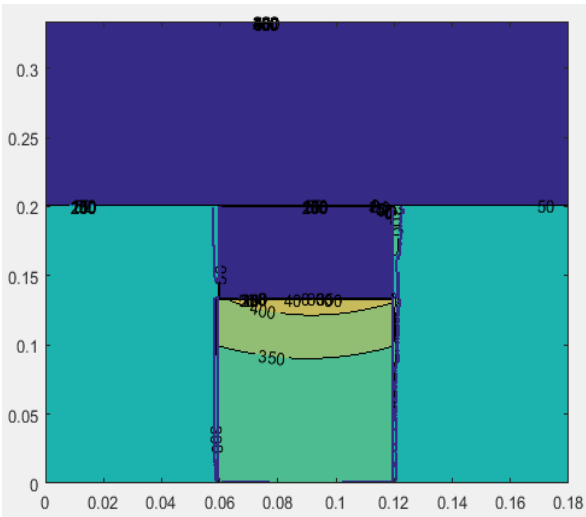

(b)

Fig. 3. (a) The temperature field in the "cryobot-ice" system at a cryobot height of $0.1 \mathrm{~m}$; (b)The temperature field in the "cryobot-ice" system at a cryobat height of $0.12 \mathrm{~m}$.

\section{Conclusion}

According to the results of the mathematical modeling, it has been established that the processes of the phase transformations (melting of ice) during the movement of a cryobot through ice structures affect significantly the temperature fields of the ice-cryobot system. It can be noted that even at a high initial temperature $(\mathrm{T}=500 \mathrm{~K})$ of the cover of the apparatus, it cools down. The results of the numerical simulation have also showed that the geometric dimensions of a cryobot have a significant effect on the characteristics and conditions of motion of the thermal drilling machine. So an increase in height leads to a significant increase in the cooling period. Accordingly, it can reasonably be assumed that, 
for stable drilling, the cryobot must possess the geometric characteristics providing the optimal thermal regime.

The work was supported by the scientific schools grant NSH-7538-2016.8.

\section{References}

1. N.I. Vasiliev, Problems of the Arctic and Antarctic, 76 (2007)

2. E.N. Chumachenko, D. Dunham, R.R. Nazirov, V.P. Kulagin, Vestnik of the Nizhny Novgorod University named after. H, I. Lobakogo, 6 (2011)

3. P. Weiss, K.L. Yung, Ng T.C., Planetary and Space Science, 56 (2008)

4. P.G. Talalay, Nature. 9 (2006)

5. G.V. Parfenova, E.N. Chumachenko, New information technologies in automated systems, 13 (2010)

6. A.S. Ovcharova, Computational technologies, 4 (1999)

7. O.N. Korolyova Dynamic adaptation in the multi-front problems of Stefan. (Abstract, 2006)

8. J.Jonsson, J. Sundqvist, H.Nguyen, Acta Astronautica, 79 (2012)

9. L. Zelenyi, O. Korablev, M. Martynov, Advances in Space Research, 48 (2011)

10. S.V. Syrodoy, N.Y. Gutareva R.I. Taburchinov, MATEC Web Conf. 72 (2016)

11. S.V. Syrodoy, N.Y. Gutareva, R.I. Taburchinov, MATEC Web Conf. 72 (2016)

12. S.V Syrodoy, N. Y. Gutareva., K.A. Bugaeva, MATEC Web Conf. 72 (2016) 